\title{
Virginity Rituals and National Development: Harnessing a Traditional Virtue to Address Modern Challenges in Africa
}

\author{
Agatha Ifeyinwa Nnazor \\ Department of Social and Behavioral Sciences, Faculty of Sociology and Criminal Justice, Central State University \\ 1400 Brush Row Road, Wilberforce Ohio 45384, USA. Email: annazor@centralstate.edu \\ Jacquelyn Price Robinson \\ Department of Social and Behavioral Sciences, Faculty of Sociology and Anthropology, Central State University \\ 1400 Brush Row Road, Wilberforce Ohio 45384, USA. Email: jrobinson1@centralstate.edu
}

\author{
Doi:10.5901/mjss.2016.v7n1s1p155
}

\begin{abstract}
Africa is grappling with poverty and unemployment. Virtually every sector of the economy is underdeveloped. African females can significantly contribute to the improvement of socioeconomic conditions in Africa considering their active traditional and historical roles in development. However, most females are not entering the formal sector of the economy and indeed the professions because of lack of or inadequate education. Many do not go to school and most do not go beyond elementary education. A significant number of girls drop out of school due to unplanned or unwanted pregnancy and sexually transmitted infections (STIS) including HIV/AIDs. This paper proposes reinvigoration of virginity rituals as a strategy for enhancing girls' participation in education and formal wage sector employment. The paper argues that revitalized virginity rituals will serve as a sociocultural incentive for girls to stay longer in school, qualify for participation in formal wage labor force and contribute more meaningfully to national development. Revitalized virginity rituals will result in a healthier African society in that it will significantly reduce sex-related vices including unplanned and unwanted teen pregnancies, complications associated with abortion and childbirth to under-aged adolescents, STIS and HIVIAIDS. The study is informed by a review of extant literature and data on women and development, women and reproductive health, women and education, and virginity rituals in Africa.
\end{abstract}

Keywords: Virginity, Virginity ritual and rites of passage, Virginity testing/reed dance, Females and national development

\section{Introduction}

Contemporary African societies grapple with numerous development challenges. On most socioeconomic development indicators including poverty level, formal sector employment, health, and education, Africa lags behind other continents (Population Reference Bureau (PRB) 2015 World Population Data Sheet, 2015; United Nations Economic Commission for Africa, African Union, African Development Bank Group \& UNDP MDG Report, 2014). The significant contributions of African females to national development, especially in the informal sector are well documented (Boserup, 1970; ChineryHesse et al., 1989; Nnazor, 1998, 1999; Vickers, 1991; United Nations Economic Commission for Africa et al., MDG Report, 2014). However, in the contemporary knowledge- and technologically-based economy, females in Africa are not sufficiently prepared through education and training to contribute to national development. The reality is that most women and girls in Africa are not entering the formal sector of the economy and indeed the professions because of lack of or inadequate education. Most do not go to school or go beyond elementary education. A number of factors including gender-biased cultural norms that privilege males over females, unequal sex roles that place more familial responsibilities and burdens on females, early marriage and high fertility rate, high cost of education and high rate of poverty, longdistance school location, safety and security of girls and women, unplanned and unwanted pregnancy, sexually transmitted diseases and HIVIAIDs affect participation of females in education (Association for the Development of Education in Africa (ADEA), 2001; Frances, 2008; Gay, 2015; Guttman, 2001; Kane, 2004; Osagiobare et al., 2015; Marteleto et al., 2008; Moletsane, 2015). Although several key factors keep many girls out of school or make it difficult for them to complete college, this paper will focus on sex- and reproductive health-related factors that limit their participation in education. 


\section{Sex-related and Reproductive Health Issues: An Impediment to Girls and Women's Education}

Unwanted pregnancy and sexually transmitted diseases, including HIVIAIDS have been identified as major barriers to the education of girls in Africa (Frances, 2008; Osagiobare et al., 2015; Marteleto et al., 2008; Moletsane, 2015; Population Reference Bureau (PRB) World Population Data Sheet, 2015). A significant number of girls drop out of school due to unplanned or unwanted pregnancies; complications associated with unsafe abortions, childbirth to under-aged girls and sexually transmitted infections (STIS) including HIVIAIDs (Economic Commission for Africa, The African Gender and Development Index, 2011; Frances, 2008). The decline in abstinence, sexual freedom, laxity and promiscuity, unprotected sex, limited use of contraceptives, female child marriage, female child rape and violence account for the high rate of teenage pregnancy in Africa.

Research on women and reproductive health indicates that typically there is a high prevalence of teen pregnancy and STIs among sexually active young females who engage in unprotected sex (Frances, 2008; Osagiobare et al., 2015; Marteleto et al., 2008; Moletsane, 2014; PRB 2002 Women of Our World, 2002; PRP World Population Data Sheet, 2014, 2015). Africa has the highest population of young and sexually active people ages $10-24$, who are also the least likely to use modern bio-medical contraceptives compared to young people from other continents. For instance, in $2013,31 \%$ of African populations were youth ages 10-24 as compared to 25\% of the world youths ages 10-24 (PRB the World's Youth 2013 Data Sheet, 2013, p. 6). About 13\% of girls ages $15-19$ and 23\% of women ages $20-24$ used modern contraceptives as compared to $22 \%$ of girls ages $15-19$ and $36 \%$ of women ages $20-24$ who use modern contraceptives worldwide in 2005/2011(PRB the World's Youth 2013 Data Sheet, 2013, p. 11). Sexually active teen females who do not use contraceptives are at higher risks of becoming pregnant and contracting sexually transmitted infections, including HIVIAIDS, which have adverse implications for their education and participation in the formal wage sector.

Africa has the highest prevalence and percentage of HIVIAIDS, especially among females with the least resources to deal with the problem (PRB the World's Youth 2013 Data Sheet, 2013; PRB 2014 World Population Data Sheet, 2014; PRB 2015 World Population Data Sheet, 2015). Of the 35.0 million people living with HIVIAIDS around the world in 2013, about 24.7 million are from Sub-Saharan Africa and the region accounts for nearly $70 \%$ of new HIV infections, globally. Women and young people account for a significant proportion of HIVIAIDS victims in Africa (WHO, 2013). For instance, data from PRB the World's Youth 2013 Data Sheet (2013) indicates that African females ages 15-24 have HIVIAIDS prevalence rates of 2.5 as compared to 1.1 prevalence rates for African males of the same age in 2011. Comparably, the world has HIVIAIDS prevalence rates of 0.5 among females and 0.3 among males ages 15-24 in 2011. Of all African regions, Southern Africa has the highest HIVIAIDS prevalence rates of 11.8 among females and 5.2 among males ages 15-24 in 2011. Eastern Africa has the second highest HIVIAIDS prevalence rates of 3.2 among females and 1.4 among males ages 15-24. West Africa has the third highest HIVIAIDS prevalence rates of 1.9 among females and 0.8 among males ages 15-24 in 2011 (PRB the World Youth 2013 Data Sheet, 2013, p. 11-12). Similarly, data from PRB 2015 World Population Data Sheet for percentage of males and females infected with HIVIAIDs, indicates that $0.9 \%$ of males and $1.5 \%$ of females ages $15-24$ are infected with HIVIAIDS in Africa as compared to $0.2 \%$ of males and $0.1 \%$ of females in Latin America and the Caribbean and $0.4 \%$ of males and $0.5 \%$ of females in the Caribbean in 2014, p.16-17). With 4.2\% of males and 8.3\% of females, ages 15-24 with HIVIAIDS in Southern Africa (PRB 2015 World Population Data Sheet, 2015, p.16-17), the region remains the top world and African region with the highest percentage of young people, ages 15-24, with HIVIAIDS. African girls' health, education, labor force participation and other socio-cultural and economic contributions to their families, communities and societies are adversely impacted when they experience unwanted pregnancy or are infected with HIVIAIDS.

Since the 1975-1985 United Nations Decade for Women, African countries and international organizations have been carrying out awareness campaigns about safe sex, contraceptives, reproductive health, and sexually transmitted infections, especially HIVIAIDS. In spite of the campaigns, teen pregnancy and sexually transmitted diseases, especially HIVIAIDS still remains a key impediment to girls' education in Africa. Consequently, an urgent challenge and imperative for African governments is how to get girls and women to stay in school long enough to qualify for participation in formal wage and professional employment. Hence, this paper proposes the reinvigoration, and promotion of virginity rituals as a strategy for enhancing girls' participation in education and formal sector employment.

\section{Harnessing the Value of a Traditional Virtue to Keep Girls in School}

Traditionally, African societies socialized young females to remain virgins, which meant that they were expected not to engage in sexual intercourse defined as penis penetration of the vagina before marriage (Blank, 2007). Typically, African societies enforced virginity through ceremonial rituals and rites of passage that range from proof of intact hymen, virginity 
testing or reed dance and circumcision (Alaba, 2004, Beckwith and Fisher, 2002; Kang'ethe, 2014). A young woman that remained a virgin until marriage was a source of pride and honor to her family and community. Loss of virginity before marriage attracted serious consequences such as social rejection, dishonor to the family, failure to secure a husband, low bride wealth, and ostracization (Alaba, 2004; Blank, 2007; Kang'ethe, 2014). Traditionally, virginity is regarded as a virtue in Africa.

\subsection{Value of the Virtue: A Structural Functionalist Perspective}

The usefulness of virginity rituals can be understood within the Structural Functionalist theoretical framework propounded by a number of sociologist including Emile Durkheim (1912), Talcott Parsons (1951) and Robert Merton (1957). Structural Functionalists conceive social practices, patterns, processes, culture and institutions in terms of their functionality and contributions to social order and stability in society (Anderson,Taylor and Logio, 2015). Social patterns, institutions, culture and practices serve some manifest (intended) and latent (unintended) functions as well as social dysfunctions for societies (Merton, 1957). Virginity rituals help African societies maintain sexual order. Manifestly, virginity and its rituals serve as protection against unplanned pregnancies among teens, and breeding of children outside marriage. Latently, virginity rituals protect girls from sexual vices and dysfunctions such as STIS and HIVIAIDS in contemporary African societies ravaged by the disease. Within African collectivist culture, virginity and lost virginity assumes a communal significance, and becomes not only an individual issue, but that of their families and the community as a whole. With virginity-engendered abstinence and sexual restraints, girls can defer or suspend marriage, complete their education and pursue careers while garnering social, financial and cultural capital they need to establish strong and stable families.

Like virginity and its associated rituals, sex has both manifest and latent consequences or functions and dysfunctions. Manifestly, sex fulfills some intended functions. It helps African societies reproduce and regenerate their human capital. Sex is also deployed for pleasure, and latently for the maintenance of male and female sexual health and wellbeing. Sex becomes dysfunctional when it is associated with negative and unintended outcomes such as unwanted pregnancy and HIVIAIDS with their concomitant adverse impact on girls' status, dignity, education and career. The burdens of manifest, latent and social dysfunctions of sexual intercourse and the concomitant adverse effects on a girl's status, career and life are borne not only by her and her sexual partner, the burdens are also borne by her and her partner's families and communities. Because of the socio-cultural, health and economic high stakes of virginity, African cultures teach that sex should be avoided or suspended until marriage.

Considering the low participation of females in contemporary knowledge- and skill-intensive economy, revitalization of virginity rituals can help to significantly increase the number of girls who stay in school, complete their studies and contribute meaningfully to national development. The section that follows discusses examples of virginity rituals among the Yorubas of West Africa, and the Zulus and Swazis of Southern Africa.

\subsection{Rituals of Chastity}

Although African virginity rituals and rites of passage can be different in some respects, their overarching goal is abstinence from sexual intercourse until marriage. Most virginity rituals and rites of passage include private seclusion of the initiated female or females for informal, indigenous sex education (Beckwith and Fisher, 2002, Kang'ethe, 2014). Typically, designated elderly women, particularly aunties or "ritual mothers" groom and socialize young females for marriage and motherhood during the rite of passage, prior to marriage (Alaba, 2014, Beckwith and Fisher, 2002; Kang'ethe, 2014, Wickström, 2010). During the period of seclusion, initiates are taught how to protect their virginity. The private seclusion is followed by public outing of initiates as they dance and are celebrated and honored for successfully transitioning from adolescence to womanhood. As initiates are celebrated in public, the families, communities and potential suitors partake and share in the joy and challenges of supporting the initiates to maintain their virginity (Beckwith and Fisher, 2007; Wickström, 2010; Kang'ethe, 2014).

While African societies differ in geography, ethnicity, religion and cultural practices, all share the commonality of valuing virginity and upholding and enforcing virginity norms (Alaba, 2004, Beckwith and Fisher, 2002; Kang'ethe, 2014). Among the Yorubas of Western Nigeria, for instance, virginity is valued and encouraged prior to marriage. Marriage to a virgin female enhances the legitimacy of her offsprings (Alaba, 2004). Female members of a bride's extended family socialized her on how to be a good wife and mother before her departure to her husbands' household. Two female kinswomen of the bride typically accompanied her to her husband's household. The women slept by the door of the bride and groom's bedroom in anticipation of the deflowering of the bride on the first bridal night and bridal cry of pain as her hymen is ruptured and blood stains the bed-spread (Alaba, 2004). In the early hours of the morning following the 
defloration night, the blood spotted sheet is covered in a calabash and returned to the bride's parents as proof of the bride's virginity. The return of the blood-stained sheet is followed by a congratulatory message to the bride's parents for properly raising their daughter. Proof of intact hymen is an occasion for jubilation and merriments by the bride's and groom's families and kinsmen and women. Non-blood stain generally results in the return of the bride to her parents with anger and disappointment from the husband and his kinsmen (Alaba, 2004).Virginity began to lose its importance in Yoruba society after the British colonization and modernization of Yoruba societies. As western liberalism, individualism and sexual freedom were introduced into Yoruba culture, virginity before marriage was deemphasized, pre-marital sex and pregnancy during courtship became the trend (Alaba, 2004). The cultural and symbolic meaning of intact hymen as a sign of virginity and the negative repercussions of non-intact hymen impel Yoruba females to strive to remain virgins before marriage. Yoruba families and communities are collectively responsible for ensuring that their daughters are not "spoilt" before marriage. Within the cultural and symbolic meaning of intact hymen virtue, the virginity of females becomes a high stake "treasure" and a virtue that must be guarded under the gaze of African mothers, fathers, uncles, brothers, and the community.

Another variant of virginity ritual related to intact hymen is virginity testing or reed dance. Virginity testing is a cultural practice among the Zulu people of South Africa and Swazis of Swaziland. It is a cultural tradition in which female genitalia is inspected to determine if they are sexually and morally chaste. Virginity testing helps to ensure that young females are married while virgins, and are sexually clean and free of STIs (Kang'ethe, 2014; Maluleke, 2012). Virginity testing entails examinations of adolescent girls' genitals as they lay on the mat in a line through the parting of their labia by local virginity experts to confirm that their hymen are intact and not perforated. A confirmation of intact hymen is viewed as a cultural milestone and celebrated by families and the community with dancing, singing and ululations (Kang'ethe, 2014; Wickström, 2010). Proof of intact hymen is also seen as a sign of the community's success in enforcing chastity, and maintaining morality that helps to curb teen pregnancy and STIs (Afolayan, 2004; Kang'ethe 2014). Girls whose virginities are confirmed are issued a certificate. Girls who fail a virginity test on grounds of suspected perforated hymens are counseled and encouraged to secure their secondary virginities in future as they mature into marriageable woman (Kang'ethe, 2014).

Virginity rituals are informal, indigenous abstinence sex education that regulates sexual intercourse, prevent unplanned and unwanted pregnancies, as well as sexually transmitted diseases including HIVIAIDs at minimal costs. The high stakes of virginity and its rituals provide a sociocultural incentive that helps to keep female teens focused on their education and in developing the competencies they need to participate effectively in contemporary knowledge-based and skill-intensive global economy.

\subsection{Critics of Virginity Ritual}

Notwithstanding the sociocultural, health, educational and economic value of virginity rituals, there are critics who hold the view that virginity rituals are primitive, harmful, oppressive and an infringement on girls' and women's rights (EvansPritchard, 1965; Goody, 1973; Huntington, 1975; Maluleke, 2012). The critics are also concerned that virginity testing is conducted under unsanitary conditions by charlatans and un-credentialed virginity test "experts" (Maluleke, 2012). Instead of virginity rituals, the critics advocate the use of modern biomedical contraceptives. The biomedical contraceptive technology the critics recommend include contraceptive sponge, condoms, pills, intrauterine devices (IUD), surgical sterilization and emergency contraception (U.S. Department of Health and Human Services, Office on Women's Health, 2012). In the view of the critics, virginity rituals are not congruous with the principles of the United Nation's Charter on Human and Women's rights and freedom. The critics, who are mostly from Western countries, tend to be Eurocentric in their view of African culture and virginity rituals. Hence they see the rituals as harmful and contributory to the marginal status and limited rights of African females. Conversely, advocates of virginity rituals (Alaba, 2004; Beckwith and Fisher, 2007; Wickström, 2010; Kang'ethe, 2014) charge that Western sex-related life-styles largely account for sexual laxity, sexual permissiveness and their concomitant sexual vices among youths in contemporary Africa. In their view, African youths have been largely influenced by the glamorization of sex and sexual freedom in Western media and culture; and the influence contributes directly or indirectly to the rather pervasive promiscuity and high rates of teen pregnancy and STIs that keep many girls out of school in Africa.

There is some evidence that bio-medical contraceptive technology has limited effectiveness. Some of the contraceptives have negative side effects and health implications for women users across the world. For instance, contraceptive sponge contains nonoxynol-9 spermicide, which has adverse effects on women allergic or sensitive to the spermicide. Non-latex and non-polyurethane condoms like natural or lambskin condoms do not protect against STIS (U.S. Department of Health and Human Services, Office on Women's Health, 2012). The critics of virginity rituals appear not to 
take into consideration the economic, ethical, moral, religious and cultural contexts within which the bio-medical contraceptives they advocate are introduced and utilized. They tend not to reckon that most African societies are rural with high rates of poverty, illiteracy, limited health care and educational services. In particular, some African families, educators, communities and leaders view the use of modern bio-medical contraceptive, especially by teens as signaling unbridled sexual freedom, permissiveness or laxity. Modern bio-medical contraceptives are also seen by some families, communities, teachers and leaders as antithetical to their cultural and religious beliefs, mores and values; and as a result, they are less likely to accept or encourage use of modern contraceptives (Francis, 2013; Mkumbo, 2014).

In light of the institutional, ethical and cultural barriers to using modern bio-medical contraceptives and adverse effects of modern bio-medical contraceptives, a significant number of Africans, especially those of modest means tend to rely on traditional virginity and virginity rituals as informal indigenous sex education to regulate sex and maintain female virginity before marriage. African virginity and virginity rituals emphasize abstinence, which is the most effective and natural protection against unplanned pregnancy, unwanted babies, and sexually transmitted infections including HIVIAIDs. Girls who abstain from sexual intercourse are more likely to avoid unplanned and unwanted pregnancies and sex-related infections. Girls' opportunities for education, self-development and participation in the relatively higher income formal sector labor force are enhanced when they are not pregnant or have to cater to unplanned babies. If reinvigorated and actively promoted, African virginity rituals can significantly reduce teen pregnancy, enhance girls' health and participation in education and the professions.

\section{Conclusion}

Africa faces enormous development challenges as it struggles to alleviate poverty, provide quality education, gainful employment and improve the health of its teeming populations. African women have traditionally contributed to the development of African societies as resource managers, community servers, reproducers of human capital and producers of goods and services in the informal sector (Boserup, 1970; Chinery-Hesse et al., 1989; Vickers, 1991, Nnazor, 1998, 1999). Many girls and women are shut out of the formal wage sector of the economy because of their limited education. An appreciable number of girls drop out of school due to unplanned pregnancy and sexually transmitted infections including HIVIAIDs. Revitalization of virginity rituals can serve as a sociocultural mechanism for significantly enhancing girls' participation in education and formal wage employment. As informal, indigenous abstinence sex education, virginity rituals are natural and cost effective means for reducing sexual vices and maintaining sexual order and stability in Africa. Virginity rituals help girls to abstain from sexual relationships, avoid pregnancy, persist in school and graduate to pursue gainful careers and contribute meaningfully to development. African governments and community leaders should help to revitalize and promote virginity with its rituals as a traditional virtue that has high value in contemporary Africa. However, efforts to revitalize and promote virginity rituals should take into account hygiene and sanitation concerns raised by critics. Virginity tests should be conducted in clean environments with appropriate and sanitized equipment. Virginity experts and ritual mothers should be formally trained and certified for the roles they play.

\section{References}

Afolayan, F. (2004). Culture and Customs of South Africa. Westport, Connecticut: Greenwood.

Alaba, O. (2004). Understanding Sexuality in the Yoruba Culture. Africa Regional Sexuality Research Seminar Series, Africa Regional Sexuality Research Center (ARSRC): 1-13. Retrieved from http://www.arsrc.org/downloads/uhsss/alaba.pdf

Andersen, M.L; Taylor, H. F. and Logio, K.A, (2015). Sociology the Essentials. 8 ${ }^{\text {Th }}$ Edition. Cengage, Learning, United States.

Association for the Development of Education in Africa [ADEA]. (2001). Working Group on Female Participation. Retrieved from http://www.adeanet.org/workgroups/en_wgfp.html

Beckwith, C. and Fisher, A. (2002). African Ceremonies: The Concise Edition. Harry N. Abrams, Inc. Publishers.

Boserup, E. (1970). Women's Role in Economic Development. New York: St. Martins Press.

Blank, H. (2007). Virgin: The Untouched History. Bloomsbury USA, New York.

Chinery-Hesse et al. (1981). Engendering Adjustment for the 1990's. A Report of a Commonwealth Expert Group on Women and Structural Adjustment. Commonwealth Secretariat, Marlborough House. Pall Mall, London.

Durkheim, E. (1912). Elementary Forms of Religious Life. Glencoe, IL: Free Press.

Economic Commission for Africa. (2011). The African Gender and Development Index, 2011. Retrieved from http://www.uneca.org/sites/ default/files/PublicationFiles/agdi_2011_eng_fin.pdf

Evans-Pritchard, E. E. (1965). The Position of Women in Primitive Societies and in Our Own. Evans-Pritchard, E.E. Position of Women in Primitive Societies and Other Essays in Social Anthropology by. Faber and Faber Ltd., London. pp, 37-57

Frances, H. (2008). Dropping Out from School: A Cross Country Review of the Literature. CREATE PATHWAY TO ACCESS. Research Monograph. No. 16. University of Sussex for International Education. 
Francis, D. (2013). Sexuality education in South Africa: Whose values are we teaching? Canadian Journal of Human Sexuality. 22(2): 69-76. doi: 10.3138/cjhs.2013.2199

Gay, Elizabeth. (2015). Evidence Can Help Make Sustainable Development Investments Strategic. Population Reference Bureau. Retrieved from http://www.prb.org/Publications/Articles/2015/poppov-inesting-in-women.aspx

Guttman, C. (2001). When girls go missing from the Classroom. The Courier, UNESCO. Retrived from http://www.unesco.org/courier/ 2001_05/uk/education.htm. May also be accessed from The Courier UNESCO at http://unesdoc.unesco.org/images/0012/ 001226/122623e.pdf, pp. 13-14

Goody, E. N. 1973. Context of Kinship: An Essay in the Family Sociology of Gonja of Northern Ghana. Cambridge England.

Huntington, S. (1975). Issues in Women's Role in Economic Development: Critique and Alternatives. Journal of Marriage and Family. Vol.37: 1001-1012

Kane, Eileen, (2004). Girls Education in Africa: What Do We Know About Strategies That Work? African Human Development Working Paper Series, Human Development Sector, African Region, The World Bank, Washington D.C.

Kang'ethe, S.M. (2014). The Need to Resuscitate Cultural Rite of Virginity Testing as a Tool to Strengthen the Campaign Against HIVIAIDS and Moral Decadence in South African Region. Mediterranean Journal of Social Sciences. 5 (8): 484-489. Doi:10.5901/mjss.2014.v5n6p484

Maluleke, M.J. 2012. "Culture, Tradition, Custom, Law and Gender Equality. P.E.R (Potchefstroom Electronic Law Journal (PELJ)/ Potchefstroomse Elektroniese Regsblad (PER)) Journal. 15 (1): 1/428 - 22/428. http://dx.doi.org/10.4314/pelj.v15i1.1

Marteleto, L., Lam, D. and Ranchod, V. (2008). Sexual Behavior, Pregnancy, and Schooling Among Young People in Urban South Africa. Studies in Family Planning. 39(4) 351-368. DOl: 10.1111/sifp.2008.39.issue-4. ISSN: 0039-3665.

Merton, R. (1957). Social Theory and Social Structure. New York: Free Press.

Mkumbo, K.A.K. (2014). Student's attitudes towards school-based sex and relationships education in Tanzania. Health Education Journal. 73(6) 642-656. DOI.10.1177/0017896913510426

Moletsane, R. (2014). The Need for Quality Sexual and Reproductive Health Education to Address Barriers to Girls Educational Outcomes in South Africa. The Center for Universal Education at Brookings Institute.

Nnazor, A I. (1998). "Women in Agriculture in Southeast Nigeria: Institutional Factors that Influence Agricultural Productivity" in Dawn H. Currie, Noga Gayle and Penny Gurstein (editors), Learning to Write Women's Studies in Development. Collective Press,Vancouver, British Columbia, Canada. pp. 158-174.

Nnazor, A I. (1999). Structural Adjustment Programmes and the Informal Sector: The Nigerian Case of Jos Women. Unpublished Doctoral Dissertation, The University of British Columbia, Vancouver, British Columbia, Canada.

Osagiobare, O. E., Oronsaye, R.O. and Ekwukoma, V. (2015). Influence of Religious and Cultural Beliefs on Girl-Child Educational Aspiration in Nigeria. Journal of Educational and Social Research. 5(2)165-170. Doi:10.5901/jesr.2015.v5n2p165

Parsons, T. (1951). The Social System. Glencoe, IL: Free Press.

Population Reference Bureau. (2002). 2002 Women of Our World, Washington D.C., USA . Retrieved from http://www.prb.org/pdf/ WomenOfWorld2002.pdf

Population Reference Bureau. (2013). The World's Youth 2013 Data Sheet. Retrieved from http://www.prb.org/pdf13/youth-data-sheet2013.pdf

Population Reference Bureau. (2014). 2014 World Population Data Sheet. Retrieved from http://www.prb.org/pdf14/2014-worldpopulation-data-sheet_eng.pdf

Population Reference Bureau. (2015). 2015 World Population Data Sheet. Retrieved from http://www.prb.org/pdf15/2015-worldpopulation-data-sheet_eng.pdf

United Nations Economic Commission for Africa, African Union, African Development Bank Group and UNDP (2014). mdj 2014 Report. Assessing progress in Africa towards the Millennium Development Goals: Analysis of the Common African Position on the post2015 Development Agenda. Retrieved from http://www.uneca.org/sites/default/files/PublicationFiles/2014_mdg_report_ summary.pdf

U.S. Department of Health and Human Services, Office on Women's Health. (2012). Birth control methods facts sheet. Retrieved from http://www.womenshealth.gov/publications/our-publications/fact-sheet/birth-control-methods.html

Vickers, J. (1991). Women and the World Economic Crisis. Zed Books Limited. London and New York.

WHO. (2013). HIVIAIDS: A Strategy for the WHO African Region. World Health Organization, Regional Office for Africa, Brazzaville. Retrieved from http://www.afro.who.int-hiv-aids-strategy-who-african-region-en-8.pdf

Wickström, A. (2010). Virginity testing as a local public health initiative: a 'preventive ritual' more than a 'diagnostic measure'. Journal of the Royal Anthropological Institute. 16: 532-550. DOI: 10.1111/j.1467-9655.2010.01638.x 